Thorax (1956), 11, 105.

\title{
PULMONARY HAEMOSIDEROSIS ASSOCIATED WITH BRONCHIECTASIS
}

\author{
BY \\ A. H. CAMERON \\ From the Department of Pathology, University of Sheffield
}

(RECEIVED FOR PUBLICATION NOVEMBER 25, 1955)

Although haemoptysis is a common clinical symptom in bronchiectasis, pulmonary haemosiderosis has not been recorded in this condition. In the two cases described in this paper, there was also morbid anatomical evidence of pulmonary hypertension.

\section{CASE Reports}

CASE 1.-A boy aged 15 years had suffered from recurrent bronchitis since the age of 6 months and bronchopneumonia almost every winter. He also had asthmatic symptoms, necessitating hospital treatment for status asthmaticus on one occasion, but the condition was not considered to be primarily of allergic or psychic origin. In recent years, his main complaints were breathlessness on exertion and a persistent productive cough. The sputum was mucopurulent, occasionally tinged with blood, and averaged more than an ounce $(30 \mathrm{ml}$.) a day. Investigation at the age of 12 revealed constant cyanosis, digital clubbing, electrocardiographic evidence of right ventricular strain, and radiological evidence of increased vascular markings with early cystic change in both lungs. Two years later extensive cylindrical and saccular bronchiectasis was demonstrated by bronchography. In July, 1953 , one month before he died, there was a period of nausea and fever. He recovered from this and his death was unexpected and sudden; he collapsed while waiting in a 'bus queue to go to school and died within a few minutes.

There had been a persistent anaemia (haemoglobin range, 10.7 to $11.8 \mathrm{~g}$. per $100 \mathrm{ml}$.) since the age of 12 , but never any jaundice. During this period there was a varying degree of polymorph leucocytosis (total white cells $9,800-17,000$ per c.mm.) ; eosinophilia was noted on two occasions with 840 per c.mm. in November, 1950 , and 1,668 per c.mm. only three days before he died.

Post-mortem examination was performed 24 hours after death. Externally, there was clubbing of the fingers and toes, and moderate cyanosis. The chest was increased in its antero-posterior diameter. Internally, the main abnormalities were found only in the thorax. Both pleural cavities were obliterated by extensive fibrous adhesions. The lungs were bulky and diffusely emphysematous and largely obliterated the cardiac surface. There were no subpleural bullae. Slicing after formalin fixation revealed bronchiectasis in all lobes but most extensively in the basal and apical segments of both lower lobes. The tracheal and bronchial mucosa was congested and the intrapulmonary bronchi showed cylindrical dilatation peripherally. In the bronchiectatic areas the small branches terminated by entering rounded cystic cavities, measuring up to $1 \mathrm{~cm}$. in diameter and often partially loculated. These cavities were lined by congested mucosa and many were filled with thick mucus, which was also found in the smaller bronchi. Further changes were particularly well demonstrated, using thin slices of whole lung mounted on paper after the method of Gough and Wentworth (1949). Groups of emphysematous air sacs were found in the bronchiectatic areas, and in the centre of these there was often a small bronchiole invested with a little black dust pigment. There was also a distinct rusty-brown pigmentation of the lung tissue in the bronchiectatic areas which gave a positive Prussian-blue reaction macroscopically (Fig. 1). The heart weighed $325 \mathrm{~g}$., the enlargement being due to marked right ventricular hypertrophy, the right ventricular myocardium measuring $1.1 \mathrm{~cm}$. in thickness near the base. There was also myocardial hypertrophy of the right atrium and both these chambers were moderately dilated. The pulmonary arteries were of normal calibre, but there was a little atheroma of the primary intrapulmonary branches. The left side of the heart was normal and there was no abnormality of the coronary arteries. There was no septal defect and the ductus arteriosus was firmly closed. The tonsils were moderately enlarged and the mediastinal lymph nodes markedly enlarged and congested. There was severe loss of cortical lipoid in both adrenals. The remaining organs showed no remarkable changes.

Histological Examination of Lungs.-Throughout both lungs there is an intense inflammatory infiltration of the bronchial and bronchiolar mucosa and submucosa ; plasma cells predominate, but in many parts there are abundant neutrophil polymorphs. The epithelium is lost in many places and in others has assumed a metaplastic low columnar, cuboidal, or squamous form. In many places the bronchial adven- 


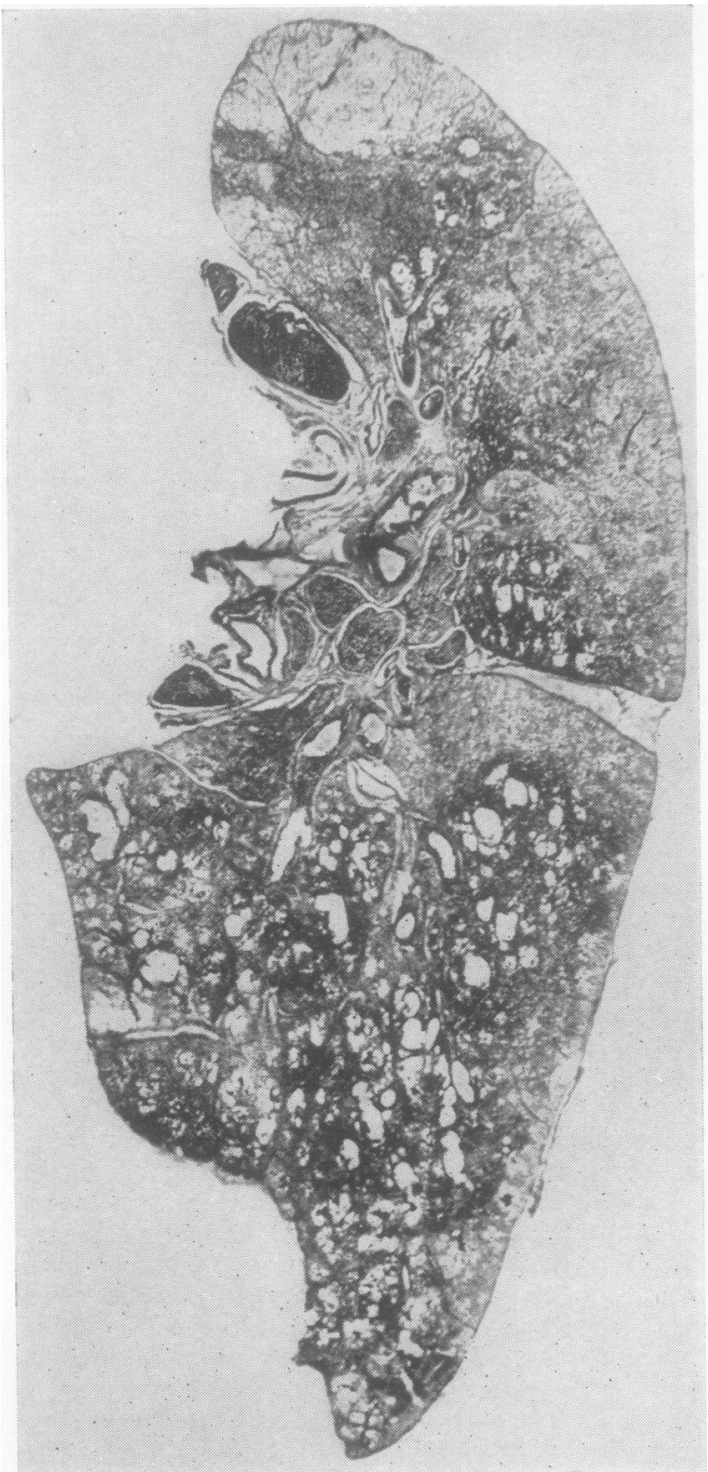

Fig. 1.-Thin slice of the left lung mounted on paper and treated with dilute potassium ferricyanide and hydrochloric acid. Bronchiectasis is particularly extensive in the lower lobe, and there is a positive Prussian-blue reaction in the lung tissue surrounding the bronchiectatic cavities.

titia is infiltrated by histiocytes and plasma cells extending into the walls of the surrounding alveoli which sometimes contain an organizing inflammatory exudate. Areas of emphysema are seen to be related to terminal bronchioles which are often invested with a little collagenous tissue containing anthracotic dust pigment. The walls of the emphysematous air sacs are thin and avascular and lacking in elastic tissue. The elastica of adjacent alveoli is in places atrophic and in places forms thickened bars at the intersections of the alveolar walls.

Hypertensive changes are found in the smaller pulmonary blood vessels generally throughout the lungs. Inconspicuous focal intimal thickening, consisting of fine elastic and collagen fibres, is present in the large elastic arteries. There is medial hypertrophy of the muscular arteries between 0.1 and $1.0 \mathrm{~mm}$. in external diameter, the muscular media comprising on the average $40 \%$ of the radius of these vessels (Fig. 2). A large proportion of the arterioles of less than $0.1 \mathrm{~mm}$. in external diameter have a distinct muscular media enclosed between two well formed crenated elastic laminae (Fig. 3). Other vessels of similar size or slightly larger $(0.08$ to $0.13 \mathrm{~mm}$. in external diameter), probably venules, but possibly very small muscular arteries, show fibrous thickening of the intima with numerous irregular, branching, and often fragmented elastic fibres in the periphery of the vessel wall (Fig. 4).

In the bronchiectatic areas there are additional changes to those described above. The bronchi and bronchioles are dilated and usually the inflammatory infiltration is more intense. In some places polypoid masses of granulation tissue replace the mucosa and protrude into the lumen (Fig. 5). These polypi contain numerous congested capillaries separated by abundant plasma cells.

Many alveolar phagocytes laden with haemosiderin are found in the air sacs; although present in large numbers they do not form focal siderotic aggregations. Haemosiderin is less commonly found within macrophages in the alveolar walls. Mineral material is found encrusting the elastica of the alveolar walls and, more especially, that of the smaller blood vessels. The vessels chiefly involved are the arterioles and those described above as being probably venules. The mineral material almost always gives a positive

FIG. 2.-Small muscular branch of pulmonary artery (externa diameter approximately $0.14 \mathrm{~mm}$.). The media is thickened and contains a few elastic fibrils. (Weigert's elastic and Van Gieson's stains $\times 350$.)

Fig. 3.-Pulmonary arteriole (external diameter approximately $0.02 \mathrm{~mm}$.). There is both an external and an internal elastic lamina enclosing a media of considerable thickness. (Weigert's elastic stain $\times 350$.)

FIG. 4.-Pulmonary venule, or possibly a small artery (externa diameter approximately $0.1 \mathrm{~mm}$.). There is collagenous thickening of the intima and the elastica around the periphery is irregular in distribution and thickness. (Weigert's elastic and Van Gieson's stains $\times 350$.)

FIG. 5.-One of the small polypoid projections in the bronchial mucosa. The epithelium is fragmentary and there is intense vascular engorgement and a dense infiltration by plasma cells. (Haematoxylin and eosin $\times 350$.)

FIGs. 6-8.-An arteriole, with an external diameter of $0.04 \mathrm{~mm}$., with a double elastic 'lamina encrusted with ferric iron, ferrous iron, and phosphates $($ all $\times 500)$. Fig. 6.-Perles' method and safranin. Fig. 7.-Turnbull's blue and safranin. Fig. 8.-Von Kossa and safranin. 


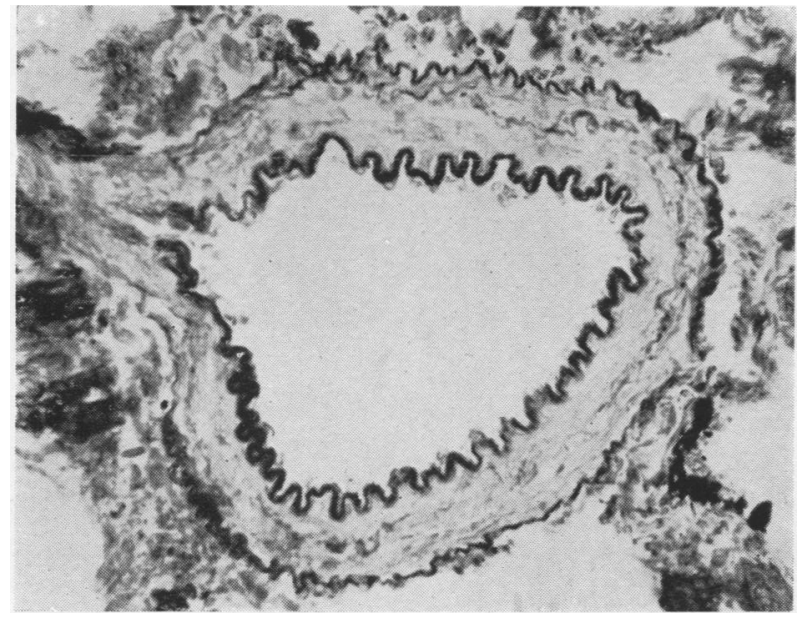

Fig. 2

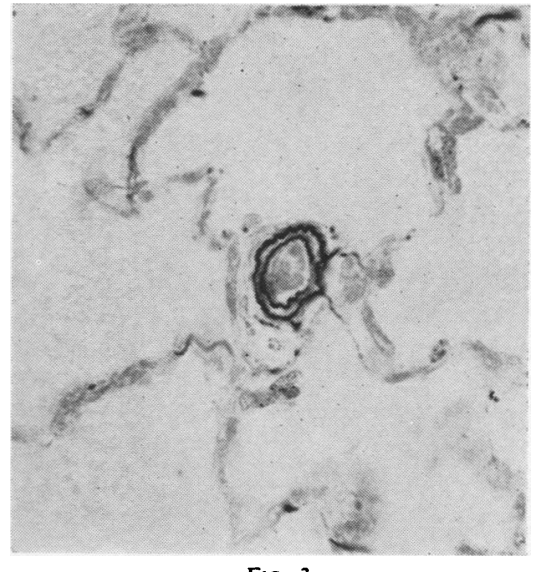

Fig. 3

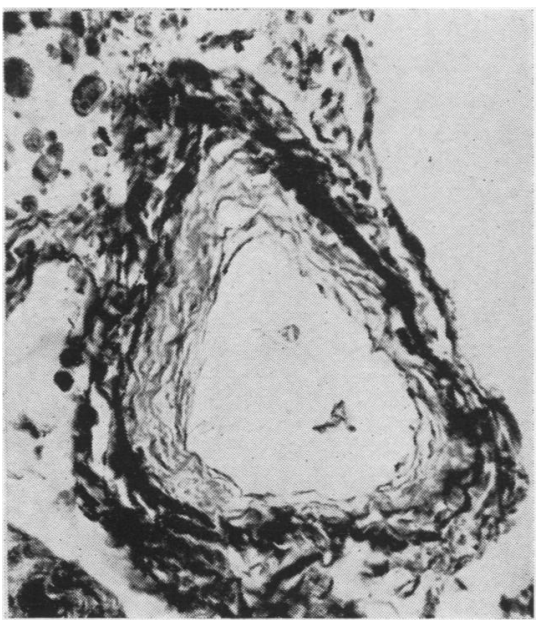

Fic. 4

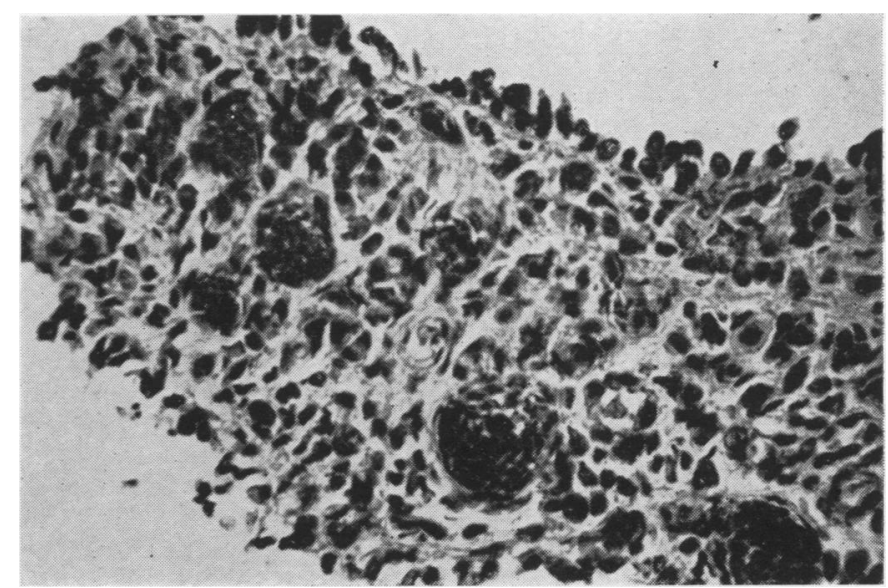

Fio. 5

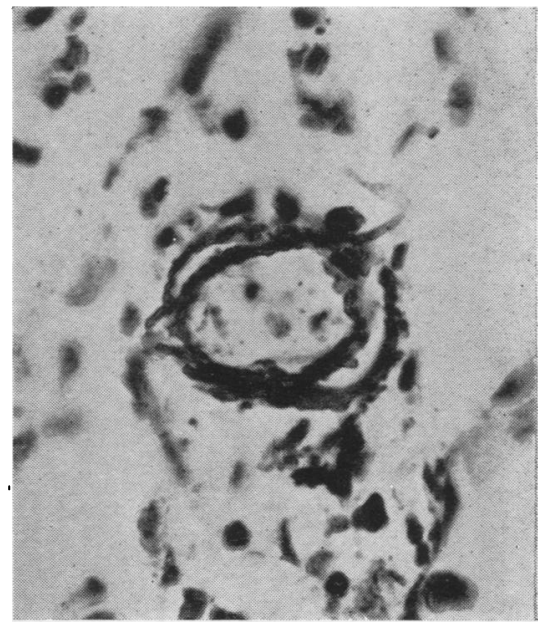

FIG. 8 


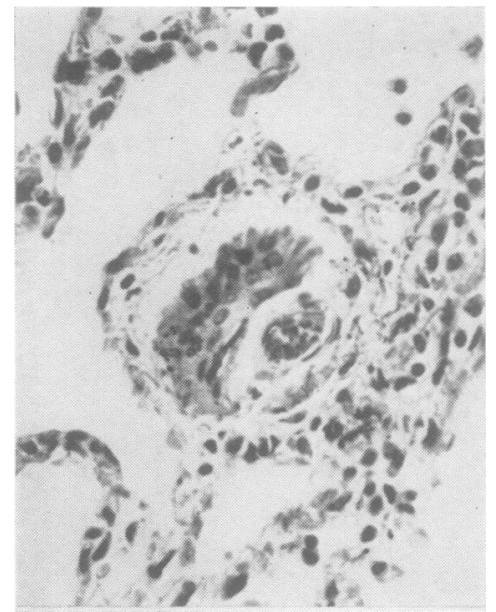

Frg. 9

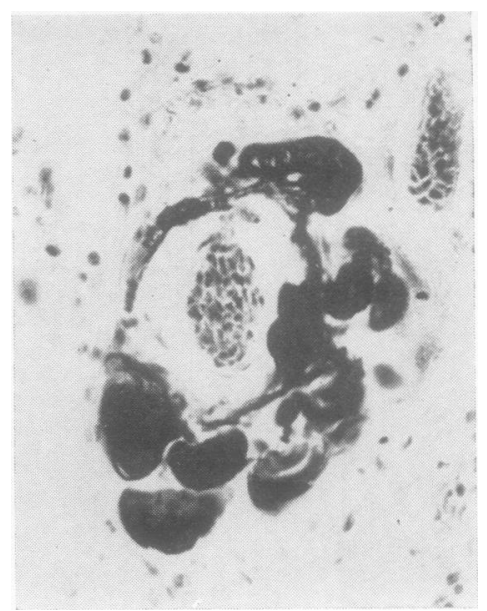

FIG. 10
FIG. 9.-Multinucleated foreign-body $\frac{O}{\bar{C}}$ giant cell containing a linear frag- $\frac{\partial}{\partial}$ ment of elastic encrusted with $\mathbb{D}$ haemosiderin. The lumen of the vessel lies to the right of the giant $\mathcal{O}$ cell and is greatly reduced in size. (Haematoxylin and eosin 350.)

FIG. 10.-Haemosiderin deposited on $\vec{\square}$ the elastic lamina of a small vessel. in probably an arteriole, and forming $\overrightarrow{0}$ rounded masses in the periphery. O (Perles' method $\because 350$.).
Prussian-blue reaction and frequently there is also a positive Turnbull's reaction for ferrous iron. It is not stained by purpurin or haematoxylin, but von Kossa's method gives a positive result in many instances, indicating the probable presence of phosphates (Figs. 6,7 , and 8 ). There is often a foreign-body giant cell reaction to these encrusted elastic laminae and fragments are sometimes seen within the giant cells (Fig. 9). Small spherical masses are found adjacent to the encrusted laminae; these give a positive Prussianblue reaction and can be stained by haematoxylin, purpurin, and von Kossa's method and therefore probably contain calcium as well as iron (Fig. 10).

CASE 2.-A man, aged 51 at the time of death, had been an underground coal-miner since the age of 14. He first became short of breath on exertion at the age of 46 , and this became progressively worse, forcing him to give up work at the age of 49 . He had had a cough for years and brought up 1 to $2 \mathrm{oz}$. (30 to $60 \mathrm{ml}$.) of grey phlegm at a time, especially in the mornings. The ankles began to swell a few months before he was admitted to hospital in March, 1955. On admission he was using the accessory muscles of respiration and was cyanosed, with cold extremities, oedema of the ankles, raised jugular venous pressure, and a palpable enlarged liver. The blood pressure was $110 / 70 \mathrm{~mm}$. $\mathrm{Hg}$, the heart was enlarged, and there was triple rhythm. There was no finger clubbing. The chest was resonant on percussion, with generalized expiratory rhonchi and crepitations at the right base. He improved a little after treatment with oxygen, penicillin, and mersalyl, but remained cyanosed and severely incapacitated by breathlessness. He went home on April 1, 1955, but was readmitted three days later in much the same condition. Moist sounds were heard throughout the chest, the jugular venous pressure became higher, and the pulse rate increased to 130 per min. before he died on April 20, 1955. Radiological examination of the chest had shown appear- ances consistent with congestive heart failure and gavecr no clear indication of pneumoconiosis.

Necropsy was performed 40 hours after death by Dr. D. E. Price. There was generalized oedema, and free fluid in the peritoneal, pleural, and pericardial $\bar{O}$ cavities. There was chronic venous congestion of the liver, spleen, and kidneys, and oedema of the intes- $\frac{\Phi}{\Omega}$ tines. The pleura was thickened and there were $\overrightarrow{\vec{B}}$ bilateral basal adhesions. Both lungs were dark, $\overline{\bar{O}}$ bulky, emphysematous, and moist. In the right lower lobe there were many bronchopneumonic areas from which beads of pus could be expressed. The larynx? trachea, and bronchi contained greenish pus, and the mucosal lining was reddish-purple and granular. The을 heart was greatly enlarged $(560 \mathrm{~g}$.) and this was due to hypertrophy of the right ventricular myocardium There was no valvular disease and the coronary. arteries were healthy.

Histological Examination of Lungs.--Sections were prepared from both upper lobes. These containo pneumoconiotic lesions consisting of mainly smalP anthracotic foci with emphysema of surroundin 8 alveoli. Collagenous fibrosis, and sometimes early ischaemic necrosis in the centre, is seen in the larger foci, but there are no whorled silicotic nodules (Fig 11). In the bronchi there is lymphocytic infiltrations of varying degree, thickening of the basement mem brane, and hypertrophy of the muscle and mucouso glands. The bronchioles are dilated and irregular ito shape. The epithelium is either lost entirely or repre sented by a scanty lining of flattened cuboidal cells The bronchiolar walls are irregularly thickened ${ }_{2}^{+}$ infiltrated with lymphocytes and histiocytes, and often contain many conspicuous foreign-body giant cells related to fragmented rods of elastic fibres which are? heavily encrusted with iron. Some of the elastiळ fibres are derived from adjacent blood vessels, but most appear to belong to the bronchiolar wall itself (Fig. 12). The musculo-elastic bundles of the brone 


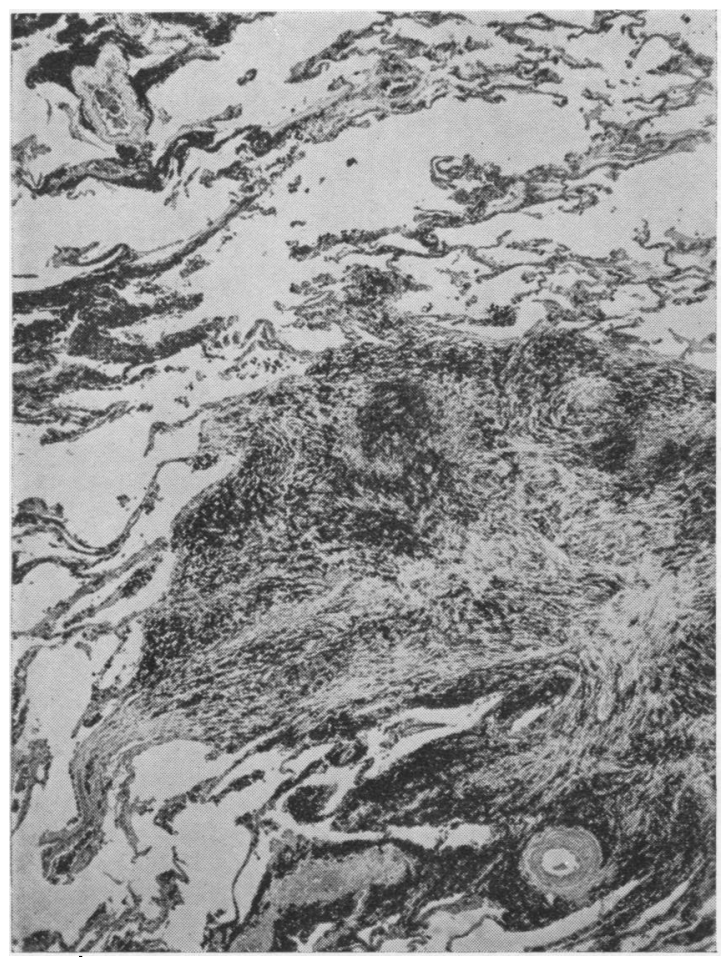

Fro. 11

chioles and alveolar ducts are often hypertrophied and encrusted with mineral.

There is a similar mineral deposit on the elastica of arterioles and small muscular arteries (Fig. 13) but there is no giant cell reaction related to the encrusted vessels. The mineral gives a positive Prussian-blue reaction for haemosiderin and sometimes a positive Turnbull's blue reaction for ferrous iron. Much of it, both in the bronchiolar and blood vessel walls, also stains with purpurin, haematoxylin,

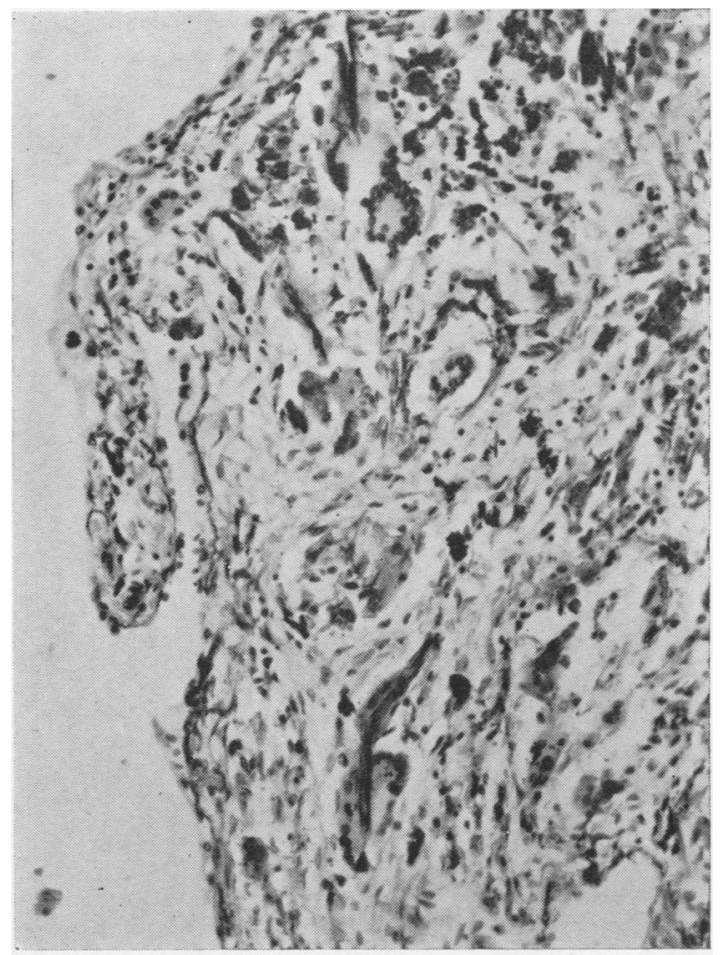

Fro. 12

and by Von Kossa's method, indicating the probable presence of calcium and phosphates (Fig. 14). Haemosiderin, not related to elastic fibres, is found within macrophages in the bronchiolar walls near the foreign-body giant cell systems, and in alveolar macrophages throughout the air sacs. Compact focal aggregates, as seen in mitral stenosis, are not encountered. The alveolar macrophages also contain abundant carbon dust. With the Prussian-blue reaction it appears that the haemosiderin and carbon dust are

FIG. 11.-A larger fibrous pneumoconiotic lesion, and two small non-fibrous anthracotic foci. There is some emphysema, and two thickened arteries are seen. (Haematoxylin and eosin $\times 26$.)

FIG. 12.-A thickened bronchiolar wall containing elastic filaments encrusted with iron and surrounded by numerous giant cells. (Haematoxylin and eosin $\times 190$.)

FIG. 13.-Haemosiderin in alveolar phagocytes and on the elastica of small arteries and arterioles. The dense interstitial material is coal dust. (Prussian-blue and safranin $\times 110$.)

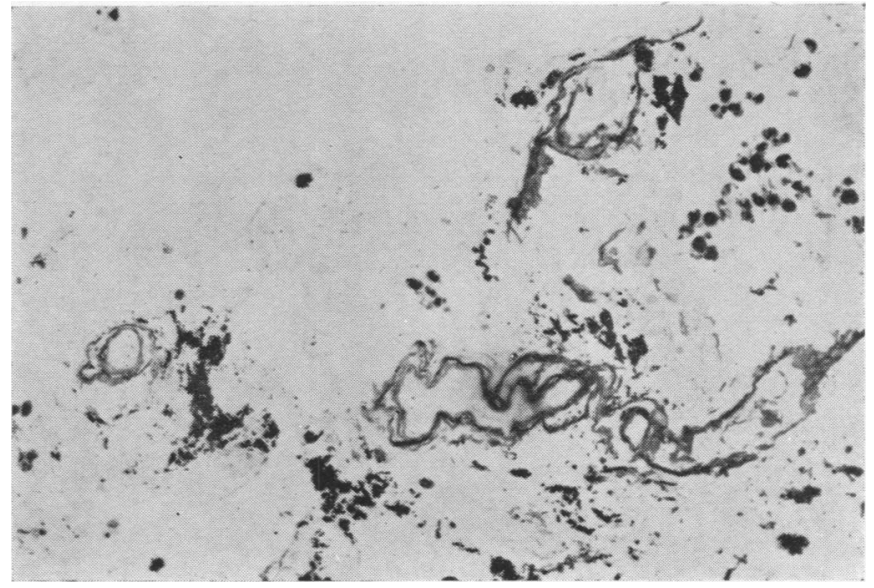

Fig. 13 


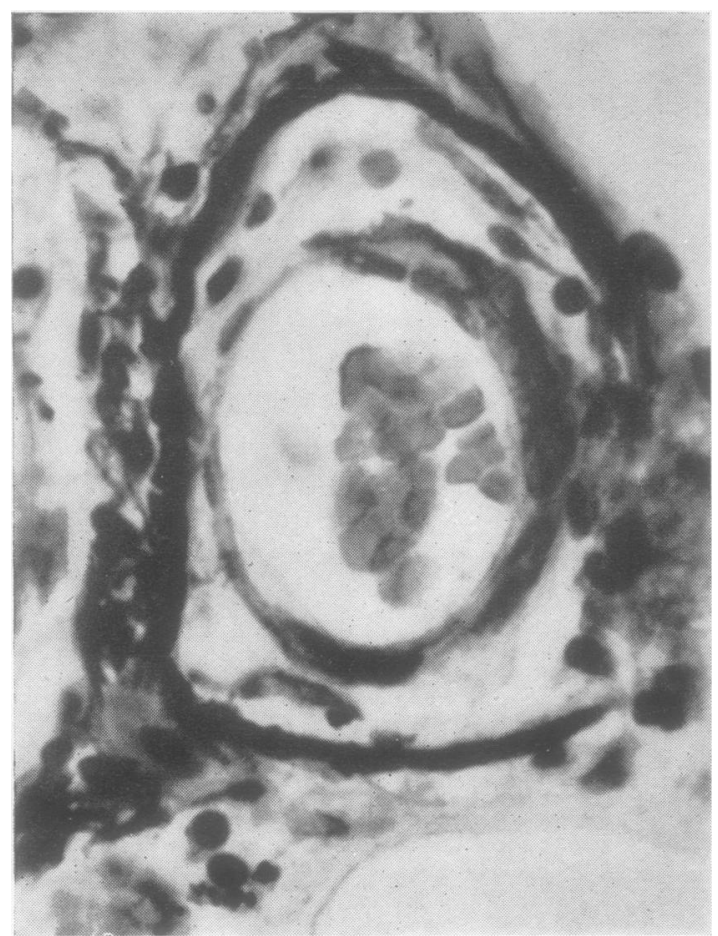

Fig. 14

present in something like equal amounts. The pneumoconiotic nodules contain no ferrous iron, ferric iron, phosphates, or calcium.

There are hyperplastic changes in the vessel walls throughout the lungs, and organizing thrombi are seen in a few elastic arteries and muscular arteries. There is fibrous thickening of the intima of the elastic arteries. The media of the muscular arteries is not obviously hypertrophied and constitutes on the average $17 \%$ of the radius of the vessel, but there is fibro-

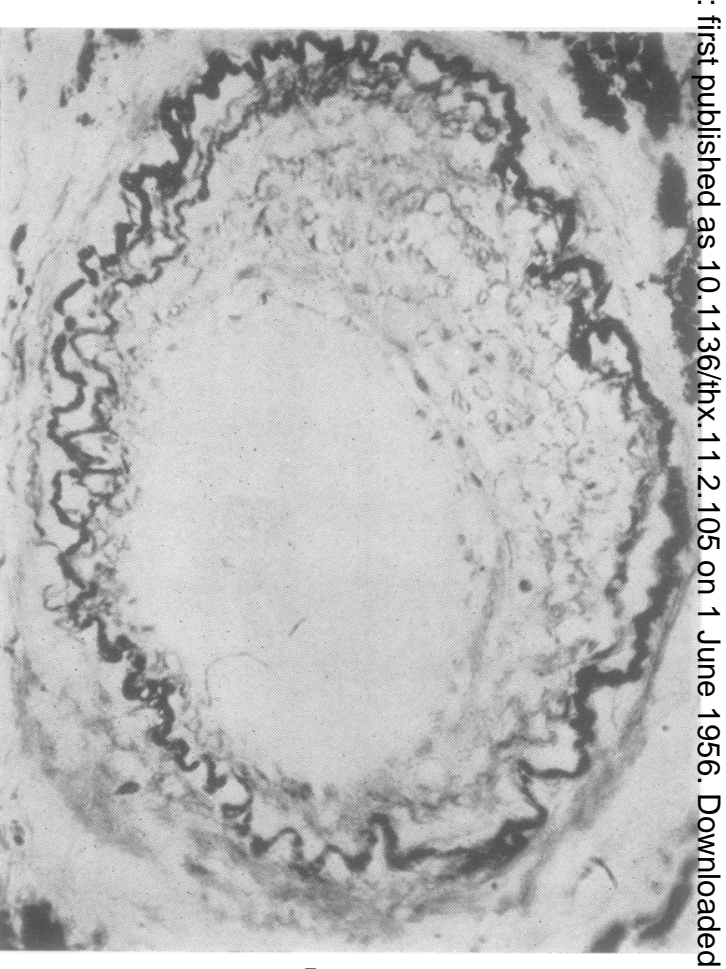

Fig. 15

elastic proliferation of the intima, varying in degree, often reducing the lumen of the vessel considerably. Intimal thickening is also observed in the muscular arteries within the larger pneumoconiotic lesions (Fig. 15). The arterioles of less than $0.1 \mathrm{~mm}$. in diameter have a narrowed lumen and a much thickened wall due either to simple cellular hyperplasia of the intima 3 . (Fig. 14) or to proliferation of fine elastic and colla-io genous fibres (Fig. 16).

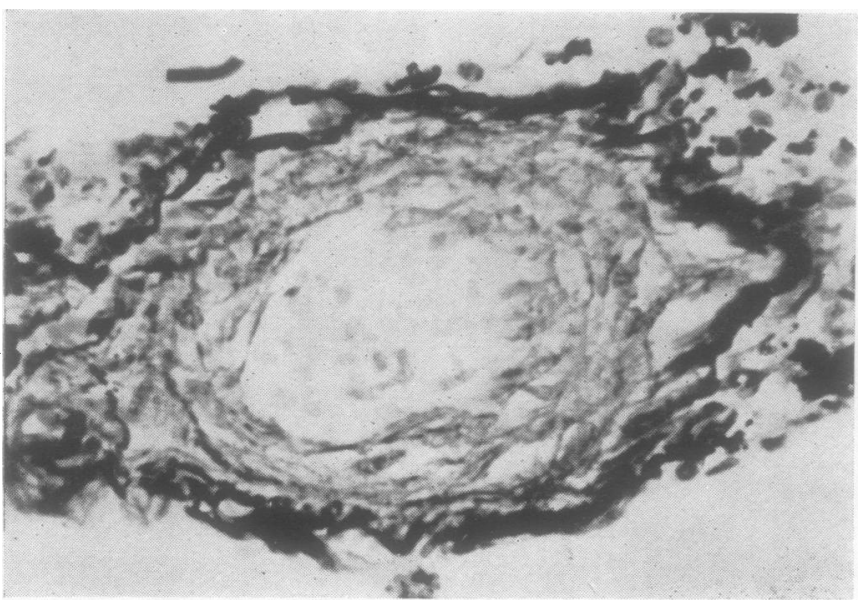

Fig. 14.-An arteriole (external diameter, $0.05 \mathrm{~mm}$.). $\mathrm{N}$ The elastic lamina is intensely stained because $O$ of encrustation with calcium. There is cellular $N$ proliferation of the intima. (Haematoxylin and $\operatorname{eosin} \times 1,000$.)

Fig. 15.-A muscular artery from a larger fibrous pneumoconiotic focus. The media is atrophic $\frac{}{C}$ and there is considerable eccentric elastic pro- $\bar{\Phi}$ liferation of the intima. (Weigert's elastic stain o) and safranin $\times 350$.)

FIG. 16.-An arteriole (external diameter, $0.08 \mathrm{~mm}$.). $\stackrel{\vec{D}}{\vec{P}}$ There is elastic proliferation of the intima and $O$ the lumen is reduced in size. (Weigert's elastic $\bar{D}$ stain and safranin $\times 550$.)

Fıg. 16 


\section{Discussion}

The right ventricular hypertrophy observed is conclusive evidence of pulmonary hypertension in these two cases, but the corresponding hyperplastic changes in the pulmonary vessels are not identical. In Case 1 the vascular changes are similar to those found in mitral stenosis. Henry (1952) found medial hypertrophy of the small arteries and muscularization of the arterioles related to the degree of mitral stenosis, and also observed intimal thickening in the small veins. Heath and Whitaker (1955) correlated similar morphological changes to the degree of pulmonary hypertension measured by catheterization. In Case 2, medial muscular hypertrophy was not observed, and the vascular changes are similar to those found in primary pulmonary hypertension by Branwood (1954) and Brenner (1935). Although McKeown (1952) found no hyperplastic changes in the small vessels in the majority of 39 cases of emphysema with cor pulmonale, the changes she observed in the remainder were similar to those in Case 2. The endarteritis affecting muscular arteries in the larger dust foci resemble those described by Wells (1954a) in areas of progressive massive pneumoconiotic fibrosis. Cor pulmonale develops commonly in progressive fibrosis but comparatively rarely in the simple type of miners' pneumoconiosis (Wells, 1954b). The miner described as Case 2 had respiratory symptoms out of all proportion to the degree of pneumoconiosis, and they must have been due to bronchitis and emphysema with subsequently developing pulmonary hypertension.

Focal haemosiderosis of the lungs occurs in mitral stenosis, and in prolonged left ventricular failure. According to Lendrum (1950) haemosiderosis does not develop in mitral stenosis unless there is right ventricular hypertrophy. Similarly, Lendrum, Scott, and Park (1950) maintain that haemosiderosis in prolonged left ventricular failure is due to relative pulmonary hypertension following a decrease in bronchial artery pressure. These authors consider that haemosiderosis is the result of haemorrhage from the walls of smaller bronchi where there is an anastomosis between the systemic and pulmonary arteries. Detailed anatomical studies of the lung by Miller (1947) suggest that there are potential capillary anastomoses throughout the bronchial tree down to the respiratory bronchioles. Miller concludes that disturbances of the normal circulatory mechanisms in the lung may cause the anastomoses to develop to a greater degree. In the two cases described in this paper it is thought that haemosiderosis was the result of haemorrhages from bronchial or bron- chiolar mucosa which was the seat of marked inflammatory changes. The pneumoconiosis in Case 2 is considered to be of little importance in the aetiology of the haemosiderosis. Applying the hypothesis of Lendrum and others (1950), it is reasonable to suggest that the associated pulmonary hypertension would increase the vascular engorgement of the inflamed mucosa and add to the risk of haemorrhage. It is probable that pulmonary hypertension is also a significant feature of Ceelen's idiopathic pulmonary haemosiderosis in children (Ceelen, 1931). Thirteen of the 16 cases examined at necropsy and reviewed by Wyllie, Sheldon, Bodian, and Barlow (1948) had right ventricular hypertrophy. It is tempting to conclude that pulmonary haemosiderosis in general is related to pulmonary hypertension, although this cannot be the only factor concerned.

The elastic tissue of the smaller blood vessels and the alveolar walls is particularly involved in pulmonary haemosiderosis, and the two cases described are no exception in this respect. Mineral encrustation of the musculo-elastic bundles of alveolar ducts was observed in Case 2, and this was a feature of Lendrum's (1950) cases. The haemosiderosis and foreign-body giant-cell reaction in the bronchiolar walls of Case 2 is unusual. Fragmentation of the bronchial elastic tissue, with a giant-cell reaction, but without deposition of iron or other mineral on the fragments of elastica, was observed by DuBois (1931) in a diabetic man of 58 with chronic bronchitis, osteomyelitis, and pulmonary abscesses. The bronch:al lesions did not appear to be related to the lung abscesses and were thought to be the result of bronchial infection. It may be that infection associated with bronchiolectasis caused degeneration and fragmentation of the elastica in Case 2, and that subsequent haemorrhage caused encrustation with iron.

The histochemical reactions of the mineral deposit in the two cases deserve comment. The most easily identifiable constituent was haemosiderin giving a positive Prussian-blue reaction, but there was also some ferrous iron shown by the positive Turnbull's blue reaction. There was also a considerable amount of phosphate staining brown-black by von Kossa's method but not staining with haematoxylin or purpurin. The mineral deposited on the elastica of the vessel walls in Case 2, and forming the spheroidal masses in Case 1, contained calcium which stained deep blue with haematoxylin and red with purpurin. The deposition of calcium and phosphates does not imply a general disturbance of the metabolism of these minerals, and there was no indication of such 
a disorder in either of the cases. An affinity between these minerals on the one hand, and iron on the other, may be recognized in many pathological states, as, for example, in the siderotic nodules of the spleen in Banti's syndrome. Bittrolff (1910) found calcium associated with haemosiderin in brown induration of the lung, but since that time attention has been primarily devoted to ferric iron. It is probable that calcium, phosphates, and ferrous iron are more commonly present in pulmonary haemosiderosis than the details of reported cases indicate.

\section{SUMMARY}

Pulmonary haemosiderosis was found at necropsy in a boy of 15 with bronchiectasis, and in a coal-miner of 51 with simple pneumoconiosis and bronchiectasis.

Cor pulmonale and hyperplastic changes in the small vessels of the lung indicated that there had been pulmonary hypertension in both patients. The hyperplastic vascular changes were of different morphological appearances in the two cases, but in both they were diffuse throughout the lungs.

In the boy, haemosiderosis was limited to the bronchiectatic areas. Haemosiderin was present in alveolar phagocytes and deposited on the elastica of alveolar walls and small blood vessels where it was associated with a foreign-body giantcell reaction.

In the adult case, haemosiderin was seen also on fragmented elastic tissue in bronchiolar walls where there was a similar giant-cell reaction.
In both cases the haemosiderosis is considered to be the result of haemorrhage from bronchial oro bronchiolar mucosa. It is suggested that pul-들 monary hypertension and inflammatory vascular $\overline{\frac{D}{n}}$ engorgement are responsible for the mucosal $\mathbb{\Phi}_{\alpha}^{\mathbb{D}}$ haemorrhage.

Attention is drawn to the presence of ferrous iron, calcium, and phosphates, as well as haemo-. siderin, in pulmonary haemosiderosis.

I wish to thank Dr. C. S. Darke of the City General Hospital, Sheffield, Dr. E. Skipper of the Beckett Hospital, Barnsley, and Dr. S. Bryson of the Sheffield $\overrightarrow{-}$ Pneumoconiosis Medical Panel, for their cooperation? in the publication of this paper. I am especially $\vec{O}$ grateful to Dr. D. E. Price, Consultant Pathologist to the Barnsley Hospitals, for providing the details of his necropsy findings.

\section{REFERENCES}

Bittrolff, R. (1910). Beitr. path. Anat., 49, 213.

Branwood, A. Whitley (1954). Edinb. med. J., 61, 332.

Brenner, O. (1935). Arch. intern. Med., 56, 976.

Ceelen, W. (1931). In Handbuch der speziellen pathologischen Anatomie und Histologie, ed. Henke, F., and Lubarsch, $\mathrm{O}$. band 3, teil 3, p. 20. Springer, Berlin.

DuBois, F. S. (1931). Arch. Path. (Chicago), 12, 222.

Gough, J., and Wentworth, J. E. (1949). J. roy. micr. Soc., 69, 231. 잉

Heath, D., and Whitaker, W. (1955). J. Path. Bact., 70, 291.

Henry, E. W. (1952). Brit. Heart J., 14, 406.

Lendrum, A. C. (1950). J. Path. Bact., 62, 555.

- Scott, L. D. W., and Park, S. D. S. (1950). Quart. J. Med., $\overline{\bar{O}}$ n.s., 19, 249.

McKeown, F. (1952). Brit Heart J., 14, 25.

Miller, W. S. (1947). The Lung, Ch. 5, 2nd ed. Thomas, Springfield, Illinois.

Wells, A. L. (1954a). J. Path. Bact., 68, 573.

- (1954b). Brit. Heart J., 16, 74.

Wyllie, W. G., Sheldon, W., Bodian, M., and Barlow, A. (1948). Quart. J. Med., n.s., 17, 25. 